\title{
COVID-19-related stigma and perceived stress among dialysis staff
}

\author{
Nalakath A. Uvais ${ }^{1} \cdot$ Feroz Aziz $^{2} \cdot$ Benil Hafeeq $^{2}$ \\ Published online: 17 August 2020 \\ (c) Italian Society of Nephrology 2020
}

Keywords Stigma $\cdot$ Stress $\cdot$ COVID-19 $\cdot$ Dialysis staff $\cdot$ India

A new strand of Coronavirus, SARS-CoV-2, has been challenging healthcare systems world-wide for the last 6 months. Healthcare workers are not just at risk of adverse physical outcomes from coronavirus disease 2019 (COVID-19), but may suffer from psychological stress.

While in several settings healthcare workers are praised as heroes, recent evidence suggests that those working in COVID-19 designated hospitals suffer from stigma from friends and family as they work in hospital environments, a high-risk area for SARS-CoV-2 contamination [1]. Moreover, stigma compounds the stress levels of healthcare staff thereby affecting job satisfaction and quality of patient care [2]. Stigma is associated with violence against healthcare workers: more than 200 attacks on healthcare workers and health facilities during the ongoing pandemic were reported by May 2020 [3]. Healthcare workers were denied access to public transport, insulted in the street, evicted from rented apartments, and even physically assaulted [3].

Like other healthcare workers, hemodialysis staff (nurses and technicians) are exposed to stress and burnout [4]. Apart from the usual stressful factors, the COVID-19 pandemic added even more factors including getting infected and stigmatised [4]. Patients on hemodialysis are at increased risk of COVID-19 infection and its complications: a recent report from China showed a 16\% COVID-19 positive rate among

Nalakath A. Uvais

druvaisna@gmail.com

Feroz Aziz

ferozaziz@gmail.com

Benil Hafeeq

benilhafeeq@gmail.com

1 Department of Psychiatry, Iqraa International Hospital and Research Centre, Calicut, Kerala, India

2 Department of Nephrology, Iqraa International Hospital and Research Centre, Calicut, Kerala, India
$230 \mathrm{HD}$ patients and $12 \%$ positivity among 33 staff members [5]. Similar data were reported from Italy [6].

In India, some dialysis units had to be closed and staff were placed in quarantine after a patient or health care worker was found to be SARS-CoV-2 positive, and stigma and misinformation on social media increased apprehension among dialysis staff. Different studies have been conducted on stress among healthcare staff during the COVID-19 pandemic and we would like to add some data exploring stigma and perceived stress in India during the pandemic. We used a snowball sampling technique to recruit participants, and designed an online self-report questionnaire using Google forms. In addition to demographic data, we added two COVID-19 pandemic-related questions regarding exposure to COVID-19 patients and history of quarantine.

A stigma scale, which measures the perceived stigma of dialysis staff regarding COVID-19, was based on the questionnaire used to study stigma among nursing staff during the Middle East respiratory syndrome coronavirus (MERSCoV) outbreak, and comprises 13 items, each of which is scored on a 5-point Likert scale [7]. Stress among the dialysis staff was assessed by the Perceived Stress Scale-10 (PSS-10) which contains 10 items, each of which is scored on a 5-point Likert scale [8]. The total score ranges between 0 and 40 , with a higher score indicating higher perceived stress.

The link to the questionnaire was sent through WhatsApp and other social media to the investigators' contacts working in dialysis units affiliated to our hospital, and the participants were encouraged to forward the survey to other staff members working in different dialysis units. The data collection was initiated on April 26, 2020 at 7:30 pm IST.

This survey gathered 335 responses between April 26, 2020, and July 7, 2020. The majority of the respondents (77\%) were between the ages of $18-30$ years, $72.8 \%$ were females, and $53.4 \%$ were married; $55.2 \%$ of the respondents were dialysis technicians and $44.8 \%$ were dialysis nurses; 
$47.2 \%$ of the respondents had 1-5 years of work experience. Furthermore, $1.2 \%$ of the dialysis staff had a history of exposure to COVID-19-positive patients, and 6.3\% had a history of quarantine following exposure. $67.2 \%$ of the respondents were living with their family during the study period.

The mean stigma score was $25.33(\mathrm{SD}=8.12) ; 183$ (54.6\%) members of the dialysis staff had a score $\geq 26$ on the stigma scale, indicating high levels of perceived stigma. The mean PSS-10 score was 17.72 (SD = 4.48), and $121(36.1 \%)$ members of the dialysis staff had a high score on this scale (score $\geq 20$ ). Pearson correlation showed a significant association between stigma and PSS-10 scores $(0.266, p<0.01)$, while no significant association was found between sociodemographic and COVID-19 related variables.

Our study showed that $54.6 \%$ of the dialysis staff perceived significant stigma associated with their job and 36.1\% of them significant stress. We could not find any studies exploring stigma and stress among hemodialysis staff during the COVID-19 pandemic. A recent study from India involving physicians explored COVID-19-related stigma and stress and found relatively higher levels of stigma (62.1\%) and stress (63.8\%) when compared to our study results [9]. Our study also found that the level of perceived stigma is significantly associated with stress among hemodialysis staff, which is in agreement with previous studies carried out among physicians and nurses during a pandemic [9]. Together, our results indicate that dialysis staff perceive high stigma during the COVID-19 pandemic, which is a novel finding with clinical, policy, and research implications. There is an urgent need for pro-active anti-stigma programs to protect health care workers so that they can continue their quality work effectively. Dialysis staff may be at higher risk of stress and stigma, and this issue should be timely addressed to prevent health care dysfunction, also considering that it may be very difficult to replace specialized members of the dialysis team in case of burnout.

Funding No financial disclosures.

\section{Compliance with ethical standards}

Conflict of interest No conflicts of interest.
Statement of human and animal rights All procedures were approved by the Iqraa International Hospital and Research Centre Institutional Review Board.

Informed consent All participants provided informed consent prior to their participation.

\section{References:}

1. Koh D, Lim MK, Chia SE et al (2005) Risk perception and impact of Severe Acute Respiratory Syndrome (SARS) on work and personal lives of healthcare workers in Singapore: what can we learn? Med Care 43(7):676-682

2. Hernandez SHA, Morgan BJ, Parshall MB (2016) Resilience, stress, stigma, and barriers to mental healthcare in US Air Force nursing personnel. Nurs Res 65(6):481-486

3. Bagcchi S (2020) Stigma during the COVID-19 pandemic. Lancet Infect Dis 20(7):782. https://doi.org/10.1016/S1473 -3099(20)30498-9

4. Karkar A, Dammang ML, Bouhaha BM (2015) Stress and burnout among hemodialysis nurses: a single-center, prospective survey study. Saudi J Kidney Dis Transpl 26:12-18

5. Ma Y, Diao B, Lv X, Zhu J, Liang W, Liu L, Bu W, Cheng H, Zhang S, Shi M, Ding G (2020) 2019 novel coronavirus disease in hemodialysis (HD) patients: report from one HD center in Wuhan China. medRxiv. https://doi.org/10.1101/2020.02.24.20027201

6. Quintaliani G, Reboldi G, Di Napoli A et al (2020) Exposure to novel coronavirus in patients on renal replacement therapy during the exponential phase of COVID-19 pandemic: survey of the Italian Society of Nephrology. J Nephrol 33:725-736. https://doi. org/10.1007/s40620-020-00794-1

7. Park JS, Lee EH, Park NR et al (2018) Mental health of nurses working at a government-designated hospital during a MERSCoV outbreak: a cross-sectional study. Arch Psychiatr Nurs 32(1):2-6

8. Cohen S, Williamson G (1988) Perceived stress in a probability sample of the United States. In: Spacapan S, Oskamp S (eds) The social psychology of health: Claremont symposium on applied social psychology. Sage, Newbury Park, pp 31-67

9. Uvais NA, Shihabudheen P, Bishurul Hafi NA (2020) Perceived stress and stigma among doctors working in COVID-19-designated hospitals in India. Prim Care Companion CNS Disord 22(4):20br02724

Publisher's Note Springer Nature remains neutral with regard to jurisdictional claims in published maps and institutional affiliations. 